\title{
Experimental and analytical study of an aluminium alloy bridge made of $1915 \mathrm{~T}$
}

\author{
Andrey Korgin, Vladimir Romanets ${ }^{*}$, Valentin Ermakov and Laith Zeyd-Kilani \\ Moscow State University of Civil Engineering, Yaroslavskoe shosse, 26, Moscow, 129337, Russia
}

\begin{abstract}
In bridge design one of the main design criteria is fatigue. Better understanding, correlation and correct design rules are important to ensure safety. New code for the design of bridge structures made of aluminium alloys are being developed in Russian Federation. The authors tested a full scale pedestrian bridge for static and cyclic loading. The results of the experiment and numerical simulation are analyzed and presented in this article.
\end{abstract}

\section{Introduction}

During the development of the code «Bridges with aluminum alloy structures. Design rules», the specialists of the Moscow State University of Civil Engineering conducted static and fatigue testing $[1,2,3,4]$ of load-bearing structures of a full-size pedestrian bridge made of aluminum alloy $1915 \mathrm{~T}$.

The goal: verification code hypothesis by computer modeling, calculations and experimental test data.

Finite element modeling was used to solve following tasks:

- Determination of critical loads on the bearing structures of the bridge.

- Determination stress strain state of the most loaded joints and bridge elements under the static and cycles loads.

- Determination of the number of cycles [5, 6, 7, 8] for a crack initiation and propagation $[9,10]$ in a construction joints using theory of project code «Bridges with aluminum alloy structures. Design rules».

\section{Experiment. Static and fatigue tests.}

The experiment model is a construction made of an aluminum alloy 1915T, consisting of two trusses and I-beams between them. Bridge has span of $10 \mathrm{~m}$ and width of $3 \mathrm{~m}$ (photo 1)

Bottom chord of trusses is made from welded beam (190x100x6x10), the top chord is made from square shaped tube with the sizes of (120x8), web are constructed using a circle shape tube. girders (welded I-beams with a size of 190x90x6x10) are fastened to the bottom chord with bolts.

*Correhosponding author: ivolodia@mail.ru 
Welding of elements of trusses is made in factory conditions in the inert gas with application of welding materials on SP 128.13330.2012. Assembly joints are made on bolts of class B, with the diameter of 8 and $12 \mathrm{~mm}$.

The scheme of the bridge and the joints characteristic are presented in Figures $1-3$.

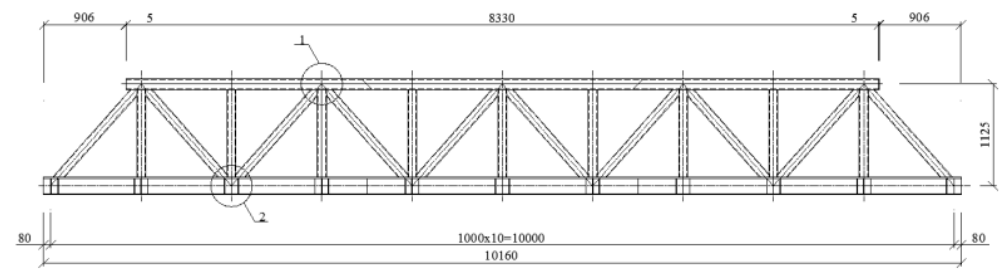

Fig. 1. The scheme of the bridge

After the delivery of the bridge elements to the testing laboratory and its assembly, measurements of the structure geometry was made to take into account possible construction deviations in the finite element model.

The bridge model was tested in a universal reconfigurable testing frame (Photo 1). The testing frame consists of a frame, a hydraulic pumping station, dynamic hydraulic cylinders with a maximum tensile / compression force of $1000 \mathrm{kN}$ and a loading control system and data collection.

Advantages of the testing frame are the possibility of applying loads in any direction, stability of load values, ease of operation, control of the applied load, etc. The tests were carried out safely for load-bearing structures by installing limiters that stop the load when the permissible movements of the rod of the hydraulic cylinder are exceeded.

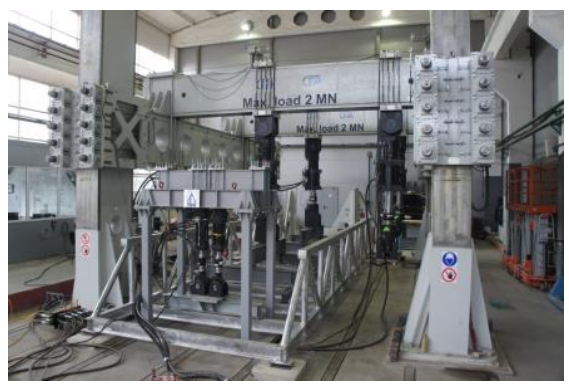

Photo 1. The bridge installed in the testing machine

Taking into account the peculiarities of the construction, in order to avoid large strains of girders, it was decided to simulate loading as close as possible to a uniformly distributed load, which is also used in the design of bridges. To solve this problem, 3 types of load distribution were designed and manufactured.

During static tests, the load was applied symmetrically using 3 hydraulic cylinders: 2 hydraulic cylinders above three level traverses with maximum force of up to $1000 \mathrm{kN}$ and 1 hydraulic cylinder above a single-level traverse with a maximum force of up to $250 \mathrm{kN}$ (Figure 2a).

During the cycle tests, the third hydraulic cylinder did not participate because of the complicated synchronization of the 3 hydraulic cylinders with increasing frequency of the load application (Fig. 2b). 


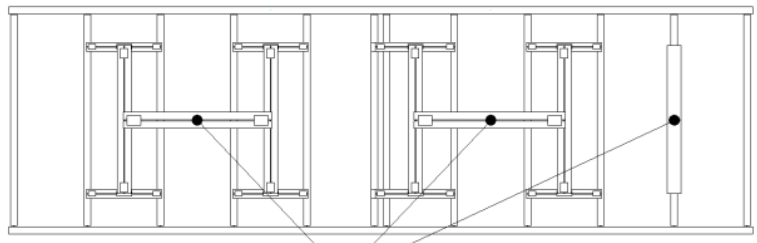

Places of application of loads

a)

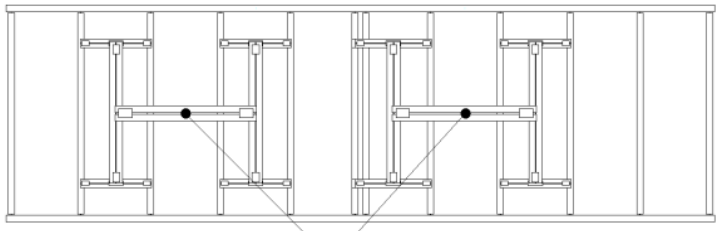

Places of application of loads

b)

Fig. 2. Schemes for applying loads to the bridge construction: a) symmetrical loading for static tests; b) asymmetrical loading for fatigue tests

During the static tests, a sequential loading was performed with the recording of these sensors every $22.5 \mathrm{kN}$ (total force from 3 hydraulic cylinders). The maximum total load was $270 \mathrm{kN}$, that is $30 \mathrm{kN}$ for each bridge run, except for the runs at the poles.

During the fatigue testing, an asymmetric loading cycle was implemented with the total force of the hydraulic cylinders from 10 to $100 \mathrm{kN}$ and the frequency of the load of $0.5 \mathrm{~Hz}$.

During the tests, the following parameters were recorded:

- Forces of hydraulic cylinders, using load cell;

- Midspan deflection of bridge, recorded using displacement sensors;

- Strain values at joints of construction, and bridge girders were recorded with strain gauges with a gage length from 1 to $5 \mathrm{~mm}$;
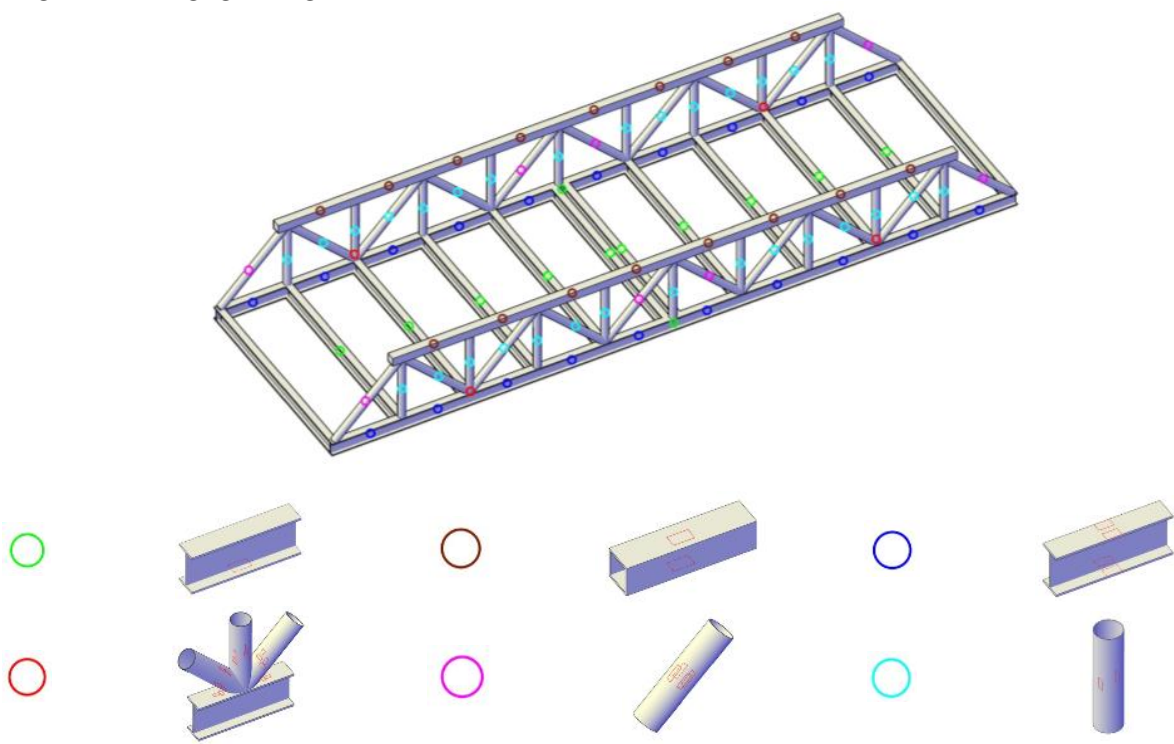

Fig. 3. Arrangement of strain gages

The total number of strain gages was 240: 2 per each truss web, 2 per each panel of the top chord, 2 to 4 per each panel of the bottom chord (figure 3). 


\section{Numerical analysis and calculations}

According to design data and measurement results, finite element models of bridge were created in the ANSYS 15.0 software package. The purpose of the calculation was to determine:

- Values of ultimate loads on the bridge

- The most stressful nodes in static and fatigue tests.

- The locations of the sensors on the physical model.

To analyze the structure behavior, a full-sized beam model and a 1/4 solid model, were created (Fig. 4). The three-dimensional finite element Solid185, which has 8 nodes of 3 degrees of freedom in each, was used in the solid model. The models were constrained as simple supported.

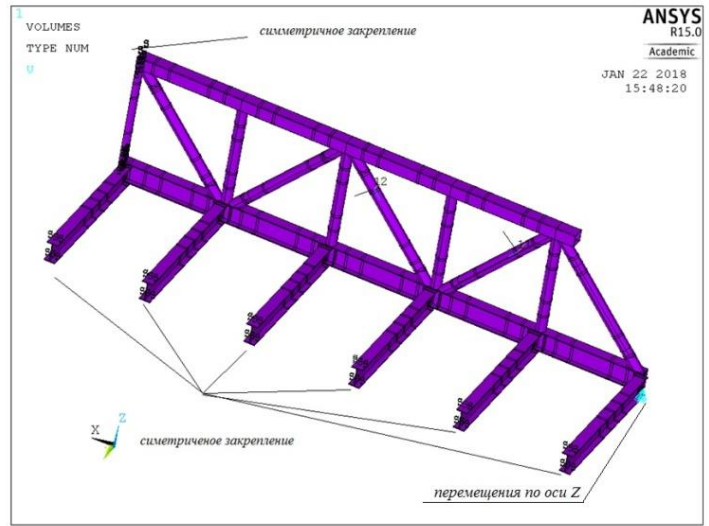

Fig. 4. FE model $1 / 4$ of the bridge of volumetric elements

The analysis was performed using material and geometric nonlinearity [11]. The loading was performed with a step of the same magnitude and an automatic time stepping until the analysis termination due to fail in convergence.

To simulate the operation of the structure, both linear (elastic modulus $\mathrm{E}=87055 \mathrm{MPa}$ and Poisson's ratio $v=0.33$ ) and non-linear behavior models of the material, obtained earlier as a result of static tests of the physical and mechanical properties of the aluminum alloy $1915 \mathrm{~T}$.

Structure modeling used both linear (elastic modulus E $=87055 \mathrm{MPa}$ and Poisson's ratio $v=0.33$ ) and non-linear (stress strain diagram, Fig. 7) material models, which were obtained earlier as a result of mechanical properties tests of the aluminum alloy 1915T.

Meshing at the joint was refined up to size of a length of a strain gage $(1 \mathrm{~mm})$ for the possibility of comparing the indications of the strains obtained by calculation and experimentally (Fig. 5).
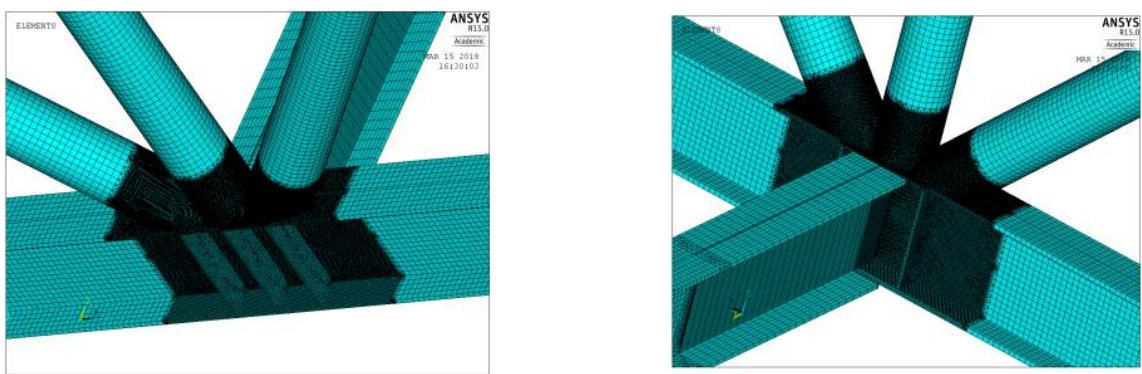

Fig. 5. The finite element grid in the most stressful node 


\section{Results and discussion}

As a result of computer modeling, the location of the most stressed elements were determined for the static and cyclic loads (Fig. 9).

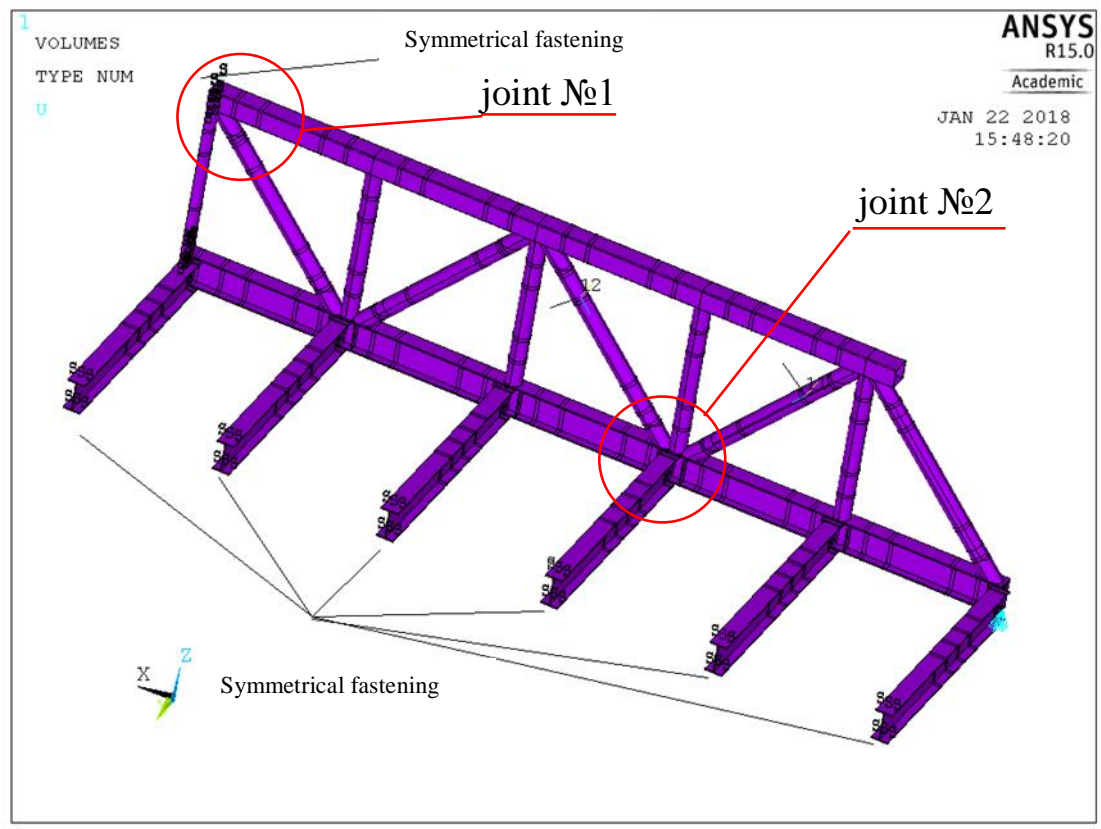

Fig. 6. The most loaded nodes

The zone of the model due to which the solution was stopped, due to unconvergence while increasing load, is the most loaded from the point of view of static tests. Top chord buckling has determined in a location of Node 1 (Figure 9)

The zone in which the maximum stress concentration is determined is the weakest point in terms of fatigue tests. The maximum concentration of stresses in node 2 (Figure 6) is due to the worst combination of tensile forces in the bottom chord and the tensioned diagonal that comes into it. The calculation showed that the concentration has a local disposition and almost fades away at the distance from the node, and practically does not affect the loadcarrying capacity under static loading.

As a result, before performing the fatigue tests joint 2 (and other symmetric to it), additional strain gauges were added to control the stresses in the concentration zones.

The stress distribution of the bridge joint is shown in Figure 7.

a)

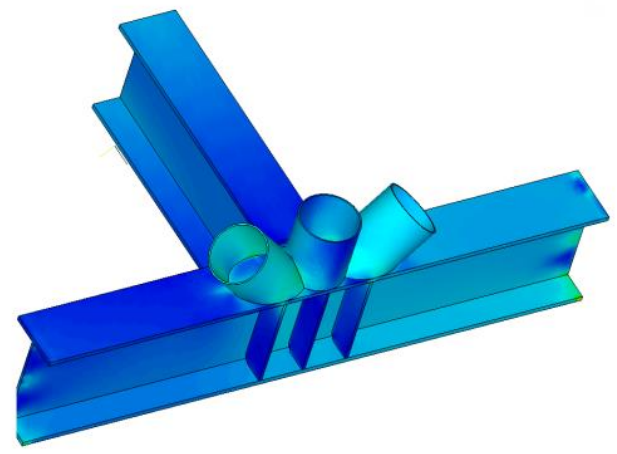


b)

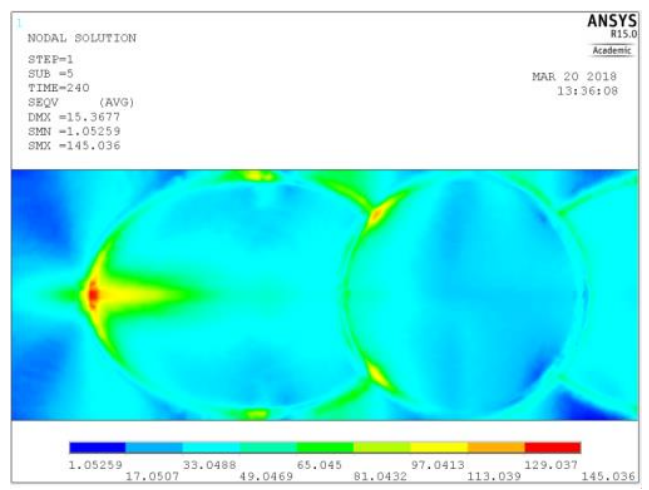

Fig. 7. Stress distribution in the bridge node in the stress concentration region

\subsection{Results of static tests}

The results of post processing the experimental and analytical data of the top chord of the trusses by static tests are presented in Table 1.

Table 1. Comparison of the strains and midspan deflection

\begin{tabular}{|c|c|c|}
\hline Load 270 kN & Experiment & Ansys \\
\hline $\begin{array}{c}\text { Midspan deflection, } \\
\text { mm }\end{array}$ & 21.07 & 20.97 \\
\hline Strain & $-1.01 \mathrm{E}-03$ & $-9.62 \mathrm{E}-04$ \\
\hline
\end{tabular}

The discrepancies between the results of the experiments and the numerical simulation testify to the correctness of finite element simulation.

\subsection{Results of fatigue tests}

As a result of the fatigue tests of the aluminum bridge, the initiation and propagation of the cracks in the joints in the three most stressed sites was recorded with the number of cycles of $180,000,240,000$ and 250,000, which indicates the correctness of the forecasts made using Eurocode calculation.

Photo 2 shows a node with a fatigue crack.

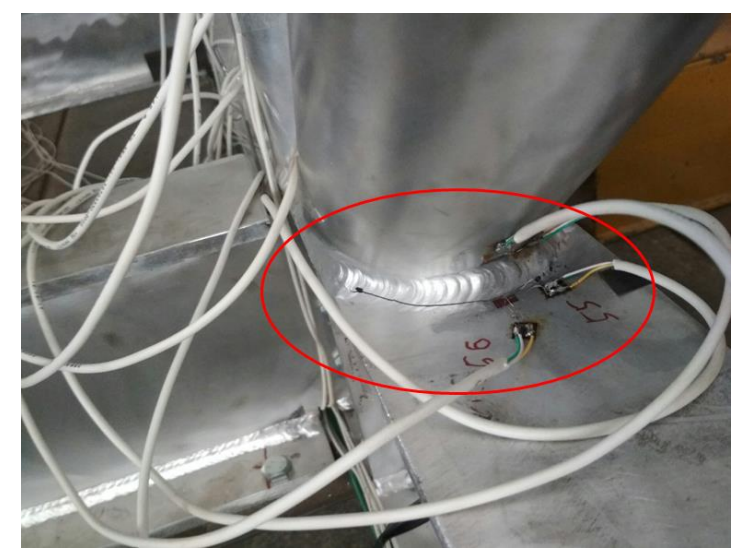

Photo 2. Node with a propagated fatigue crack

The calculation was carried out according to the project Code of Rules "Bridges with aluminum alloy structures. Design rules». 
Initial data for calculating the number of cycles before the appearance of a crack:

1. The minimum and maximum nominal stresses are obtained from the calculation $\sigma_{\text {min }}=8.02 \mathrm{MPa}$ and $\sigma_{\text {max }}=45,7 \mathrm{M \Pi a}$.

2. The standard number of cycles of the endurance limit is $2 \cdot 10^{6}$.

3. Limit amplitude $\sigma_{\mathrm{a} 0,5}=9 \mathrm{MPa}$ and parameter of the angle of inclination of the fatigue curve $m_{1}=3,4$ is taken from the table of groups of elements in accordance with the layout of the element and the location of the calculated section.

4. The stresses $\sigma_{0}=150 \mathrm{MPa}$ and $\sigma_{-1}=100 \mathrm{MPa}$ are taken from the table of the project code of rules for the $1915 \mathrm{~T}$ alloy based on the fatigue tests carried out.

5. Coefficient of reliability in the quality of manufacturing of the elements $\gamma_{\mathrm{Mf}}=1$ for rolling and extruded sections.

6. The coefficient of reliability in the quality of compounds $\gamma_{S f}=1,3$ for argon-arc semi-automatic welding in an inert gas environment.

The permissible coefficient of reliability for endurance is determined by the equation:

$$
[\mathrm{Z}]=\gamma_{\mathrm{Mf}} \cdot \gamma_{\mathrm{Sf}}=1 \cdot 1,3=1,3
$$

The amplitude and average stress of the cycle $\sigma_{\mathrm{a}}, \sigma_{\mathrm{m}}$ is determined by the equation:

Calculation of the asymmetry coefficient

$$
\begin{gathered}
\sigma_{\mathrm{a}}=\frac{\sigma_{\max }-\sigma_{\min }}{2}=\frac{45,7-8,02}{2}=18,84 \mathrm{MPa} ; \\
\sigma_{\mathrm{m}}=\frac{\sigma_{\max }+\sigma_{\min }}{2}=\frac{45,7+8,02}{2}=26,86 \mathrm{MPa} ;
\end{gathered}
$$

$$
r=\frac{\sigma_{\min }}{\sigma_{\max }}=\frac{8,02}{45,7}=0,175
$$

Angular coefficient of the amplitude diagram $\psi_{\sigma}$

$$
\psi_{\sigma}=\frac{2 \cdot \sigma_{-1}-\sigma_{0}}{\sigma_{0}}=\frac{2 \cdot 100-150}{150}=0,333
$$

Limit amplitude $\sigma_{\mathrm{c}}$ for a symmetric cycle $(\mathrm{r}=-1)$ :

$$
\sigma_{\mathrm{c}}=\sigma_{\mathrm{a} 0,5} \cdot\left(1+3 \cdot \psi_{\sigma}\right)=9 \cdot(1+3 \cdot 0,333)=18 \mathrm{MPa} ;
$$

Angular coefficient of an asymmetric cycle

$$
\varphi_{\sigma}=\frac{1-\mathrm{K}}{1+\mathrm{K}}=\frac{1-0,175}{1+0,175}=0,701
$$

Actual reliability factor for endurance $\mathrm{Z}$ :

$$
\mathrm{Z}=\frac{\sigma_{\mathrm{c}}}{\sigma_{\mathrm{a}} \cdot\left(1+\frac{\psi_{\sigma}}{\varphi_{\sigma}}\right)}=\frac{\sigma_{\mathrm{c}}}{\sigma_{\mathrm{a}} \cdot\left[1+\frac{\left(2 \sigma_{-1}-\sigma_{0}\right) \cdot(1+\mathrm{r})}{\sigma_{0} \cdot(1-\mathrm{r})}\right]}=\frac{18}{18,84 \cdot\left(1+\frac{0,333}{0,701}\right)}=0,647
$$

Expected number of cycles before occurrence of cracks for a given type of cycle:

$$
\mathrm{N}_{2}=2 \cdot 10^{6} \cdot\left(\frac{\mathrm{Z}_{\sigma}}{[\mathrm{Z}]}\right)^{\mathrm{m}_{1}}=2 \cdot 10^{6} \cdot\left(\frac{0,647}{1,3}\right)^{3,4}=187120 ;
$$

The method of number of cycles calculation that is used in a Code of Rules "Bridges with aluminum alloy structures. Design rules») showed an accurate results, 187120 cycles in theory and 180000 in experiment.

All tests were carried out using research equipment of The Head Regional Shared Research Facilities of the Moscow State University of Civil Engineering (RFMEFI59317X0006).

\section{References}

1. H. Wang, H. Gao and S. Qin, Fatigue performance analysis and experimental study of steel trusses integral joint based on multi-scale FEM, Engineering Review, vol. 37, issue 3, pp. 257-262, (2017) 
2. S. Cai, W. Chen and M. M. Kashani, Fatigue life assessment of large scale T-jointed steel truss bridge components, Journal of Constructional Steel Research, vol. 133, pp. 499-509, (2017)

3. A. Schumacher and A. Nussbaumer, Experimental study on the fatigue behaviour of welded tubular K-joints for bridges, Engineering Structures, vol. 28, pp. 745-755, (2006)

4. I. Okura, N. Hagisawa, O. Okada and S.Yamaguchi, Static and fatigue behavior of the connections of aluminum decks to steel girders, Shingo, (2018)

5. R. Coughlin, Fatigue of Aluminum Welds In Canadian Highway Bridges, A thesis presented to the University of Waterloo, (2010)

6. C. Motz, O. Friedl and R. Pippan, Fatigue crack propagation in cellular metals, Int. J. Fatigue 27 (2005) 1571-1581.

7. M. Brochu, Y. Verreman, F. Ajersch, and D. Bouchard, High cycle fatigue strength of permanent mold and rheocast aluminum 357 alloy, International Journal of Fatigue, vol. 32, pp. 1233-1242, (2010)

8. X. Zhu, A. Shyam, J. Jones, H. Mayer, J. Lasecki, and J. Allison, Effects of microstructure and temperature on fatigue behavior of E319-T7 cast aluminum alloy in very long life cycles, International Journal of Fatigue, vol. 28, pp. 1566-1571, (2006)

9. K. S. Chan, Roles of microstructure in fatigue crack initiation, International Journal of Fatigue, vol. 32, pp. 1428-1447, (2010)

10. J.R. Rice, Mechanics of crack tip deformation and extension by fatigue, In: Fatigue crack propagation. ASTM STP 415, Am. Soc. Testing Mats.,. p. 247-306 (1967)

11. A.V. Korgin, U. I. Kudishin, L.Z. Zeyd Kilani Determination of limit load bearing capacity of rod metal structures. IJAER Volume 10 pp43139-43142 (2015) 